\title{
EL «DRET REAL DE ALMOXARIF», EN LA «BATLIA GENERAL DE ORIOLA Y ALACANT»
}

\author{
Felipe Mateu y Llopis \\ Catedrático de Universidad
}

Agradeciendo la invitación de doña María Luisa Cabanes, directora del Departamento de Historia Medieval de la Universidad de Alicante, me es muy grato insistir sobre el Llibre de Capitols ab los quals se arrenden y collecten los drets Reals que te sa Magestat en la Governació y Batlia general de Oriola y Alacant. Impres en Oriola per Augusti Martinez. A despesses de sa Magestat. Any 1613 (1).

Como se indicó alli, es tal el interés de esta obra que se propuso analizarla más detenidamente y este es el objeto aquí expuesto.

Tres son las unidades territoriales en que se desarrolla la historia orcelitana, la Governació, la Batlia o Baylía y el Obispado, de las que recientemente se ha tratado por diversos autores, siguiendo la línea tradicional (2).

Ahora se centra la atención en la Batlia o Baylia y en ella en el dret de almoxarif, del que se ocupó Ocaña en 1613, sin olvidar que en 1614 Francisco Alvarez escribió un Tratado contra el Libro titulado Almojarifazgo que compuso el Dr. Luis de Ocaña.

La figura de Ocaña tiene el extraordinario relieve que acreditan las Licencias y Dedicatorias de su libro. En 19 de agosto de 1613 Pere Montañes, D. en sacra Theologia, Canonge en la santa Esglesia de Oriola, Vicari general y Official de dita Ciutat y Diocesis de Oriola, per lo molt Illustre y Reverendissim señor frare D. Andreu Balaguer Bisbe de dita Ciutat y del Consell de sa Majestat daba licencia para imprimir dicho libro, el del Doctor Luys de Ocaña, Cavaller Assessor per sa Majestat de dita Batlia general, el qual llibre de comissio nostra fonch $y$ es estat vist $y$ examinat 
perlo P. frare Pere luan Zaragoza de Heredia, mestre en sacra Theologia, y Rector del Collegi de nostra Señora del Socors y de sen loseph, Orde de Predicadors en la present ciutat de Oriola.

Lo primero que debe observarse en la obra que se considera aqui es la pulcritud de su lenguaje, la corrección de su estilo, la propiedad de su ortografía, manifiesta, por ejemplo, en el uso de las mayúsculas para los sustantivos representativos de cargos o conceptos varios, las minúsculas para los adjetivos, la puntuación tipográfica y el uso de foliación, no de paginación, al estilo clásico.

La Ciudad de Orihuela - Oriola entonces- pesaba en las altas esferas; cabeza de una Gobernación igual en categoría a la de Valencia, tenía en aquel año por Gobernador a Don luan Ferrer de Calatayud señor de la Baronia de Quart, Cavaller de la Orde y milicia de nostra Señora de Montesa y sen lordi de Alfama Comanador de Ademus y Castell Fabib, Claver de dita Orde, y del Consell de sa Majestat; era Portant veus de General Governador enlo present Regne de Valencia deça Xexona, quien recibió la Real lletra de Felipe III, dada en Madrid en 15 de diciembre de 1611 , ordenando que se estampasen los Capitols de Ocaña, obedeciendo al interés que habia por la ordenación de la Real Hacienda y conservación del Real Patrimonio; el rey decía así: Governador, los de la junta Patrimonial del Partido de Origuela, me han hecho instancia (como sabéis) para que mande al Doctor Luys de Ocaña, Assessor de aquella Baylia general, haga estampar los capitulos con los quales se arriendan en el dicho partido mis derechos reales, de Almoxariffe, Duana, Vedado, drecho de Pesos, Servicio y Montazgo, y Estremeño, por andar segun dizen, escritos de mano, y tan mal tratados que a penas se pueden leer.

Continúa la carta dando pormenores formularios y mandando al Maestre Racional de mi Regia Corte, en esse Reyno, que pasara en cuenta al Receptor lo que por esta razon hubiera pagado.

Todo el tratado está escrito en lengua valenciana, nostron parlar, como decía Ocaña, pero cuando se dirigian al Rey escribían Origuela, con natural pronunciación de Oriuela, como Orihuela.

Esta tenía extraordinario relieve por sus instituciones; se conservan los sellos de la ciudad, 1468; de la Gobernación, 1694; de la Universidad, 1799, entre los que se hallan fuera de sus archivos (3).

La legislación de la época, referente a derechos, en el sentido de tributos, en valenciano drets, era copiosa y venía de antiguo. Pedro IV en 1340, daba el privilegio de la Almoyna para sufragar la armada contra el rey de Marruecos; en 1351, en el volumen Tacha real del Consell de Valencia, como recogió el Catálogo de la Exposición de Derecho histórico del Reino de Valencia, Fernando II proveía sobre el Asesor del Baile, assessor del Batle, por la trascendencia de esta función (Privilegio 4, fol. 213, del Aureum Opus) como De potestate baiuli generalis (Priv. 31 del fol. 228). En 1488-1509 se reunían en un volumen los documentos sobre 
impuestos, censos, violarios, moros, embajadas al rey, bandos, censos del General, moneda, deudas, y otros extremos, en el Archivo del Reino de Valencia (Real, 6550, Exposición, p. 118). De 1490 a 1703 es el registro de Mercaduries y Dret vell, de la Generalidad (A.R.V. y Expo. 127) (4).

Asuntos de Orihuela pasaban ante el Consejo de Aragón; una enumeración de algunos de ellos es: En 1566, obispado de Orihuela, vacante (A.C.A.; C.A. leg. 651/2-1). En 1588, Provisión sobre la Gobernación de Orihuela (A.C.A., C.A. leg. 651-32).

1589: Provisión de la recepta de la Baylía general de Orihuela (leg. 647, 1/1-2). 1589-1694: Recepta de la Baylía de Valencia. De 1596-1694 los Capítulos sobre los derechos de peaje, quema, lezda, italianos y saboyanos (A.C.A., C.A., vol. 161; en Expo. D. Histórico, p. 207); los Capitols de Ocaña se ocuparon de los extranjeros que se avecindaron en Orihuela. La Generalidad de Valencia tenía los Llibres dels drets nous.

En 1609 la Junta Patrimonial de Orihuela, titulada Junta Patrimonial de la Ciutat y Provincia de Oriola, solicitaba la impresión de los Capitols citados. En 1611 Provisión del Oficio de Receptor de la Baylía de Orihuela y administración de las Salinas de La Mata (leg. 653/114) (5).

En 1626 Dret del General de entrada tarifa y aranzel, por el tercio ofrecido al rey en las Cortes de aquel año (Exp. p. 130); en 1627 Crides dels Capitols conferents per a la administracio y exaccio del nou dret del General del vi introduhit pera la paga del servici offert per lo present Regne a sa Magestat en les Corts celebrades en la vila de Monço en lo Any M.DCXXVI (EXp. p. 30).

Ante el Consejo de Aragón, en 1653, del Oficio de Alcaide de la Aduana del puerto de Alicante (leg. 646, 32-1-4). En 1646 del receptor de la Baylía de Orihuela con la relación de entradas y salidas (leg. 657, 30-1-6).

En 1656 "para que se pague una renta de la Recepta de Origuela" (leg. 646, 34). En 1659 sobre la competencia entre los Tribunales de la Gobernación y Baylía de Orihuela por el conocimiento de una barca de moros presa por mallorquines (leg. 648/16-1-6). En 1667-1691 Personas para receptor de la Baylia general de Alicante (leg. 646, 51/1-4).

De 1671 la Tarifa dels preus y pesos de les mercaderies per a la millor cobrança de la sissa de pas que es collecta en les Taules (exp. 207). De 1692 a 1692 la Recepta de Alicante y Salinas de La Mata (leg. 646, de C.A. en A.C.A.). De 1608 a 1718 los Llibres de drets nous, de la Generalidad de Valencia (Exp. 127). De 1640-1643, por los arrendadores de los derechos nuevos de aquélla (Exp. 225).

Index rerum

El Llibre de Capitols no lleva un índice de materias sino una breve Taula dels drets Reals que es arrenden en la present Batlia general de Oriola y Alacant, la que remite a los folios y dice así: Dret Real de Almoxarif a cartes I. Dret Real del Vedat, a cartes 113. Dret Real de Servicio y 
Montazgo, 130. Dret Real del Estremeño, o de mig Delme, 143. Dret Real de Pastura, 150. Dret Real de Pesos de Peix, 153. Dret Real de Aduana, 156. Dret Real de saca y venda de la sal de les Salines de la Mata, 178 (4).

Por la extensión de la materia se trata aquí sólo del Amoxarif, pero el índice que sigue se refiere a todo el libro y va a modo de glosario, debiéndose observar que se respetan las mayúsculas del original, del impreso, comentando cada voz cuando lo requiere su calidad, esto es, cuando no necesita explicación por ser términos comunes, remite al folio, pues no va paginado, sin precisar si es recto o verso, para mayor brevedad; el autor puso cartes, que era la forma del manuscrito usada para su foliación; cuando no se indica es que se halla passim en el Llibre.

A

Advocat patrimonial, 72: "deu coneixer si lo tal nou vehi se es avehinat pera defraudar to dit dret, del Almoxarif».

Africans, 85: los procedentes del Norte de Africa, Argel, Túnez.

Albarà de Guia, 51. "Albarà de Guía del General y fermat del Arrendador o Colector del dret Vedat", 94.

\section{Albarà del Desmero, 69}

Almoxarif 6. Ocaña lo define así: "A Inteligencia y declaracio del primer Capitol, fa advertir que Almoxarif es vocable Arabich, y significa en nostron parlar y es lo mateix que Colector de drets y rentes Real „; remite a la ley 25 título 9, párrafo 2, a Gregorio López y a Montalvo y añade «y axi la exactio de aquest dret te principi de temps que España era de Moros, ut Montalvus et Greg. sup. d. 1.25 fol. mihi 28"; "y per ara es Colecta dit dret Real de Moxarif, y se ha y deu pagar per tots aquells qui no tinguen franquea, a raho de un sou per lliura lo venedor, y altre sou lo comprador, $y$ lo mateix es dispost en lo Capitol, 9, infra eodem e aço si son Christians. Perque si son Moros, lueus o altres infeels los tals dehuen pagar a vint I dines per lliura, ço es lo venedor, vint dines, y lo comprador vint dines, si los dos son infeels segons se troba dispost en la declaracio antiga del primer Capitol de dit dret» (7).

Almojarifazgo, de Granada, 21. Almojarifazgo de Carthagena, 37. Almojarifazgo de Murcia, 52. Amprius, de la Ciutat de Valencia, 89. Aparadors, 30. Aragoneses, 85, los naturales de esta Corona. Aranzel, passim.

Archiu de la Batlia general de Oriola, 24, 97. Archiu de la Ciutat de Oriola, 34. Archiu de la Sala y Consell de la Ciutat de Oriola, 64. Ocaña escribió Archiu como forma correcta y derivada de Archivum.

Armades Reals, 10, armades de sa Magestad, 23, la Marina del rey. Arrendador de drets Reals, 30, passim; era el arrendatario, en castellano; Reals por referirse al rey.

Arrendador del dret de Almoxarif, 71, 72 
Arrendaments de drets Reals, 108. Assessor, 34. Avehinaments, 84. Los decidian los lurats de la ciudad que declaraban la franquea del nuevo avecindado: «a hu de Alacant o de Valencia o de altra ciutat, vila o lloch del Regne o fora lo Regne» había de «portar acte de Notari, com se es desavehinat", de otro lugar.

B

Baiulus, passim, 74, era el batle, pronunciábase bal.le, castellano bayle con y griega por el diptongo. Baiulus generalis, 74. «Batle general de la Ciutat y Regne de Valencia»; otro era el "Batle general de la Ciutat de Oriola y Alacant».

Barata y cambi, 68; benifet ecclesiastic, 25.

Batlia general de Oriola, 97. Batlia general de Valencia, 97. Baylia general d'enlla Xixona, 80; es la de Orihuela y Alicante, 81 ; bens mobles, 10; bens setis, 8. Bisbe, 25. Bisbe de Oriola, 104: «Lo señor Bisbe y Capitol de Oriola tenen y han lo delme del preu del arrendament del dret Real de Almoxarif. Lo señor Bisbe y Capitol, ni los Sindichs y procuradors no poden demanar dit delme davant altre lutje que lo Batle, ni executar per altra Cort, y la raho ibi".

C

Cabrits, 70; cafissos de forment, 106; Capitol, 11, 25; Capitaneus generalis, 74 .

Carregues de llenya, 12, era una medida de áridos; Cartes de censal, 37; Causes patrimonials, 80: «que no se evoquen a la Real Audiencia sino que les lexen a la Baylia general della Xixona y les evocades restituyen a la dita Baylia", lo dispuso Carlos I en 30-VIII-1555.

Catedral de Oriola, 105; censals, 8, 20; Castellans, 85; clergues, las excepciones, 10; cognició dels traus, 100; Collector, 46, «Lo Batle te obligació de nomenar Collector dels drets Reals tostemps que no hi haura arrendador", 46.

Comissio del General: refiérese a la Diputació de la Generalitat; Comissio de la Ciutat, 71; comprador, passim, Conductor, el encargado de la percepción de los drets, su administrador; véase Arrendador, 29; confiscació, 39, 101.

Contracte, 17; contrafaents, 12; contraventors, passim; correu, 34; Cort de la Batlia, passim; cossari acostumat a anar y fer viatges o camins, 101; casos de pena, confiscación o absolución; christians, passim, los que no eran jueus o moros, como habitantes o vecinos; consell de Aragó, 3. 
Delme, 143; desmero de Castilla, 11, 31; deutors, 38; diner a cens, 8; donacio en contemplacio de matrimoni carnal o esperitual, 9; "mercaduries privilegiades» que «no necessiten de albara del Desmero de Castella, y per no portar dit albara no se li pot demanar dit dret de Almoxarif"; escrivanies, 11; dret comu dels romans, 6, 89; dret de Duana en la Ciutat de Alacant, 24, 31, 91; dret de leuda, 24, 76; leuda, lleuda o lezda, tributo pagado por paso de mercaderías por las puertas de la ciudad; dret de peatje, 76; dret Real de Quema, 31, 39, 40, 95; dret Real del.Almoxarif, passim. Sobre el dret de quema: "Ultra que lo dit Real privilegi del Rey en Jacme el 2 cap. 128 sols parla del dret de Leuda, y peatje no es pot estendre al dret Real de Almoxarif que es dret diferent, y de Provincia separada, jatsia de present unida al Regne, 6»; dret vedat, 9, 94, 95.

\section{E}

Esclau de galeres, 34; esclaus fugitius, 12; esdeveniments jurisdiccionals com fruyts, 32, rentas; empenyaents, 19; pignoraciones. Escrivà, passim.

F

Familiars del Sant Offici, 9; fermança, passim; fieler dels delmes, 105; «Lo Batle de Oriola cobra del fieler dels delmes del graner de Oriola sinch cafisos forment del delme del donatiu per salari dels arrendaments que fa»; fira, 38, 39; era de privilegio real: «dins los quinze dies de la fira, los quals començen en dita ciutat dia de tots Sants primer de Noembre, y fenexen quinze de dit mes»; remite al Supremo Real Consell de Arago, que dio Sentencia in contradictorio judicio, "entre parts de una lo sindich de la ciutat de Oriola, y de altra lo procurador fiscal de sa Magestat", en 17 octubre 1567, «la qual insertada en lo llibre de lletres y provisions Reals, recondit en lo Archiu de la Sala y Consell de la ciutat de Oriola, a cartas 270"; forments, 31, 70; Francesos, 63: «per sentencia Real del Supremo Consell de Arago poden ser admesos per vehins com no sien en frau»; franquea, 75, 84: la conceden los lurats de la ciutat de Oriola, a petición de los que querían avecindarse; frau, fraus, passim; fraudar dret, 32; fruyts, 9.

Gabela, 32; como vectigal; Generalitat, 73; Graner de Oriola, 105; Guardes que poden portar armes, 71; Guardes de qualsevol drets reals, 71; Gubernator generalis, 74. 
Habit de Alcantara, 32; habit de Calatrava, 3; habit de Montesa, 32; habit de Santiago, 32; hereus, 12; hostals, 30.

Ingleses, 84: “Pero que-s dira de un Ingles, o Africa que es vengut de terra de infiels y ses batejat en Oriola o Alacant estos tendran obligacio de portar acte de desavehinament de son natural, o seran tenguts per vehins y domiciliats del lloc hon seran batejats, y traure sa franquea"; era como acta de nacionalidad; imposició, passim; era el pago de los tributos. lueus, los no cristianos ni moros, en la triple población.

$J$

Juhi, passim; jurar de fals; jurats de la ciutat de Oriola, 84; jutjes commissaris, y Visitadors del Real Patrimoni, en 1568, 106; jutjes de la Generalitat, jutjes del General, 73; jutje secular, 90; jutje Ecclesiastic, 10.

L

Ley, Iley, 78; lleys de Castella, 110, 111; Ileuda, 24; lochtinent: Lugarteniente y Capitán General del Reyno de Valencia, 98; /lch, passim; llogaters, 11; lliures de seda, 15; lluisme, 20.

M

Maçer, macero; Maestre racional, 98; Magestat del Rey, 7; mandes o lexes, 9; Manifest, 51, declaración; March, y mig march, 105 ve obligat lo arrendador de donar a sa Majestat, ultra del preu que ha donat per son arrendament, $y$ es lo march tres per cent, que ve a ser trenta per miller. Menestrals, 9; Mensa episcopal; Mercaderia, mercaduries preses en frau, 71; mercaderia franca; mesada, 100; Moneda, 90; Moriscos, expulsión, 111; Moros: "lo Moro y tot infiel que es batejard es tengut per vehi y natural del lloch hon es batejat»; adquiría carta de vecindad.

Moxarif: «Lo dret Real del Mojarif de la ciutat de Oriola y de la Vall de Elda. Deu exigir é rebre dit collector, o Arrendador de qualsevol merceries se venen e compren en la ciutat de Oriola, e son terme un sou per lliura del comprador exceptat les mercaderies que es venen en la dita ciutat e terme de aquella, per aquells qui tenen Franquea».

$\mathrm{N}$

Naturals de Oriola, 86, 87; negotiationis causa, 88; notari, 64; nou vehi, 
72: “lo nou vehi es tengut de manifestar al Arrendador del Almoxarif dins los sinch anys primers de son avehinament totes les compres y vendes que fara".

$\mathrm{O}, \mathrm{P}, \mathrm{Q}$

Obra pia, 9; pabordre, 25; pactes, 19; pacte de revendre, 9; pacte formal de vendre, 17; pechers, 31; peix de la Albufera, 32; pena de perdicio, 48; penes pecuniaries, passim; piamontesos, 62; portantveus de general governador, 98; preu cert, 47; privilegi clerical. 28; pregó real, passim; Procurador fiscal y patrimonial, 7, 48, 80, 107; Provincia de Oriola, 72; quint, 7; quitament de censal: «no es degut dret de Almoxarif».

$\mathrm{R}$

Real Audiencia de Valencia, 110; Real lletra, Real Provisio. Reals, 71, 78: "los reals que es paguen al Almoxarif de mudar la casa del Regne de Valencia al de Castella, son Valencians de a diguit dines, y no Castellans, et ratio $i b i, 8$; son los dihuytens o dieciochenos, o sea sueldo y medio, moneda valenciana».

Receptor, 98; recisió de venda perfeta, 9; Regne, 76; Rentes reals, 111; revendes, 19, 81: "de le revenda es degut dret de Almoxarif"; rey, 27; robes, 9.

$S$

Salvateria, 12, 88, 89: «lo qual se comet, comprant home franch en son nom y franquea per a home pecher, afi de escusarlo de pagar los drets Reals»; Sant Offici, 16; saques de llana, 18; sentencia, 64; sentencies de refactio, 11; Senyor Rey, passim; Sindich de la ciutat de Oriola, 39, 45; sises, 56; solució, 28; pago; sous, 34; subhastar, 11; subrogat: como Ilochtinent. Supremo Real Consell de Aragó, 63, 79.

$\mathrm{T}$

Taula, 91; Taulager, 91; tenders; terme, 22; traginer qui portara peix a vendre a la pescateria, 67; traginer o carreter qui lleva ab sa bestia o carro roba en frau, 22, 67; treta de dines, 31: saca de moneda; tracte y promesa de vendre o permutar, 9.

$\mathrm{U}, \mathrm{V}$

Universitats, 87; vectigal, 6; vehi, passim; vehinat; venda de censals, 9; vendre en gros; vendre en menut; venedor, passim; verguer, 34; virrey, 27; viles: ales viles de Elig Crevillent Asp Novelda y totes les demes de la Vall de Elda son del districte de Oriola», visitadors del Real Patrimoni, 106. 


\section{NOTAS}

(1) Véase loanna, Infanta de las Españas, Princesa de Portugal y la Baylia General de Oriola, "Saitabi", Universidad de Valencia, Facultad de Geografía e Historia, XXXI, 1981, p. 89-98; y El Llibre de Capitols ab los quals se arrenden y collecten los drets Reals que te sa Magestat en la Governacio y Batlia general de Oriola y Alacant, de Luis Ocaña, en "Historia medieval ", Anales de la Universidad de Alicante, N. 3,1984 , Departamento de Historia medieval, p. 261-275. Corrigenda: p. 264, léase Nullo vicino; 266. Dera orovisio: 268: Moli de Rovella; 269: de aquella ciutat y Regne; y: no es degut ni es exegeix; 270: deputatos generalis regni; 272: sia tengut; 273 : de venir recta via; 274 : cap de Server.

(2) En 1933 en un opúsculo titulado El Pais valencià, escrito a solicitud de una colección, se expuso, sintéticamente, la división del Reino en Gobernaciones forales; y Portantsveus de las mismas: "La governació de Valencia era regida per un Portantveus de governador general de la Ciutat y Regne de Valencia" y la de Oriola per un atre Portantveus que era titolat'Portantveus de governador general de la Ciutat d'Oriola y Regne de Valencia " la primera comprendia desde el río Cenia hasta Xixona; la segunda, llamada d'enllà Xiona, desde ésta hasta el limite del Reino con el de Murcia. Recientemente, 1981, Juan Bautista VILAR, en Orihuela. Una ciudad valenciana en la España moderna. Historia de la Ciudad y Obispado de Orihuela, Prólogo del doctor SEBASTIAN GARCIA MARTINEZ, editada por la Caja de Ahorros de Ntra. Sra. de Montserrate, de Orihuela, trae en el tomo IV, volumen III, en XIX Dinámica institucional (I) Gobernación y baylia oriolanas, p. 743-749, la historia de las mismas, con otra bibliografía.

(3) VASE Antonio DE LA TORRE, La Colección sigilográfica del Archivo de la Catedral de Valencia, "Archivo Arte Valenciano" (1915). Araceli GUGLIERI NAVARRO, Catálogo de sellos de la Sección de Sigilografia del Archivo Histórico Nacional, Madrid, 1974, III, núm. 2062.

En el Archivo Histórico Nacional se conserva el Cartulario de Orihuela bajo el título Privilegia per serenissimos Reges civitati Oriolae conssessa; se compone de 354 folios más los indices: letra del siglo XIV; miniaturas con las armas de Aragón y de la Ciudad de Orihuela; en el fol. 146, una representando a la ciudad sitiada por las tropas de Castilla, durante la guerra entre Pedro el Cruel y Pedro el Ceremonioso; contiene privilegios otorgados por Alfonso $X$ de Castilla, Pedro el Ceremonioso y otros monarcas aragoneses.

(4) Del dret de Almoxarif no trata la Gran Enciclopedia de la Región Valenciana, ni antes la Novísima Recopilación (1805). En MATHEU Y SANZ, De Regimine, el concepto se halla bajo vectigalia. También falta almoxarif en el Indice de materias del Catálogo de la Exposición de Derecho Histórico del Reino de Valencia, pero se halla Luis de Ocaña en pág. 275 y Orihuela en números 27, 37, 38, 96, 176, 275, 303, 308, 314, 372, 614, 759, 970.

Moxarif venia de mushrif, tesorero, trátalo Robert I. BURNS en su Medieval colonialism. Post crusade Explotation of Islamic Valencia, Princeton University Press, 1975, p. 251-252.

(5) Sobre éstas, documentación en A.R.V. Bailia, véase Emilia SALVADOR ESTEBAN, La comercialización de la sal en el Reino de Valencia durante la época foral moderna, en "Estudios dedicados a Juan Peset Aleixandre", 1982, p. 519-540.

(6) Sobre glosario diplomático, véase Titula de Felipe Mateu y Llopis, Universidad de Barcelona, 1985, p. 37-42.

(7) Ibidem, p. 47-62, amplia información sobre moneda. 